\title{
Allicin inhibits transient outward potassium currents in mouse ventricular myocytes
}

\author{
HONG CAO $^{1-3}$, CONGXIN HUANG $^{1,2}$ and XIN WANG ${ }^{1,2}$ \\ ${ }^{1}$ Department of Cardiology, Renmin Hospital of Wuhan University; ${ }^{2}$ Cardiovascular Research Institute, Wuhan University, \\ Wuhan, Hubei 430060; ${ }^{3}$ Department of Gerontology, Tongji Hospital, Tongji Medical College, \\ Huazhong University of Science and Technology, Wuhan, Hubei 430030, P.R. China
}

Received November 30, 2014; Accepted January 14, 2016

DOI: $10.3892 /$ etm.2016.3116

\begin{abstract}
Allicin is the active constituent of garlic, a widely used spice and food. The remedial properties of garlic have also been extensively researched and it has been demonstrated that allicin is able to inhibit the transient outward potassium current $\left(\mathrm{I}_{\mathrm{to}}\right)$ in atrial myocytes. However, the direct effect of allicin on $\mathrm{I}_{\mathrm{to}}$ in ventricular myocytes has yet to be elucidated. In the present study, the effects of allicin on $\mathrm{I}_{\text {to }}$ in ventricular myocytes isolated from mice were investigated, using the whole-cell patch recording technique. The results revealed that $I_{\text {to }}$ current was not significantly suppressed by allicin in the low-dose group $(10 \mu \mathrm{mol} / \mathrm{l} ; \mathrm{P}>0.05)$. However, $\mathrm{I}_{\mathrm{to}}$ was significantly inhibited by higher doses of allicin $(30,100$ and $300 \mu \mathrm{mol} / \mathrm{l}$; $\mathrm{P}<0.05$ vs. control; $\mathrm{n}=6$ ) in a concentration-dependent manner $\left(\mathrm{IC}_{50}=41.6 \mu \mathrm{mol} / \mathrm{l}\right)$. In addition, a high concentration of allicin $(\geq 100 \mu \mathrm{mol} / \mathrm{l}$ ) was able to accelerate the voltage-dependent inactivation of $\mathrm{I}_{\mathrm{to}}$ in mouse ventricular myocytes. In conclusion, the present study revealed that allicin inhibited the $\mathrm{I}_{\text {to }}$ in mouse ventricular myocytes, which may be the mechanism through which allicin exerts its antiarrhythmic effect.
\end{abstract}

\section{Introduction}

Allicin is the active compound in garlic, a well-researched remedy that is widely used as a spice and food $(1,2)$. It has been reported that garlic may reduce cholesterol levels, lower blood pressure, inhibit platelet aggregation, activate fibrinolysis and prevent atherosclerosis, while it also has antioxidant and anticancer effects (3-12). Garlic has also been reported to have an antiarrhythmic effect $(13,14)$, which has been observed in ventricular and supraventricular arrhythmias (13). The incidence of ischemia/reperfusion-induced ventricular fibrillation in isolated perfused rat hearts was found to be reduced

Correspondence to: Professor Congxin Huang, Cardiovascular Research Institute, Wuhan University, 99 Ziyang Road, Wuchang, Wuhan, Hubei 430060, P.R. China

E-mail: huangcongxln@163.com

Key words: allicin, transient outward potassium current, mice by garlic powder (15). Garlic significantly decreases the upper limit of vulnerability of ventricular fibrillation and improves defibrillation efficacy in a dose-dependent pattern $(16,17)$. Martín et al (18) revealed that allicin inhibited the myocardial contraction and slowed the sinus rhythm. In a further study, Martín et al (19) demonstrated that garlic dialysate was able to prolong the effective refractory period and the sinus node recovery time of isolated rat atria, in addition to suppressing premature ventricular contractions and ventricular tachycardia in ouabain-intoxicated canines.

A study by Deng et al (20) revealed that allicin was able to inhibit transient outward potassium currents $\left(\mathrm{I}_{\mathrm{to}}\right)$ in human atrial myocytes. However, the direct effect of allicin on $I_{t o}$ in ventricular myocytes has yet to be elucidated. Therefore, in the present study, the effects of allicin on $\mathrm{I}_{\text {to }}$ in ventricular myocytes isolated from mice were investigated, using the whole-cell patch clamp recording technique to test the effect of allicin on $\mathrm{I}_{\mathrm{to}}$, as detected via $\mathrm{I}_{\mathrm{to}}$ amplitude and kinetics, including $\mathrm{I}_{\mathrm{to}}$ activation, inactivation and recovery.

\section{Materials and methods}

Ethical approval. All animal procedures were approved by the Institutional Animal Care and Use Committee at Renmin Hospital of Wuhan University (Wuhan, China). The animals used in the present study were male C57 mice, aged 8-10 weeks.

Drugs and solution. Tyrode's solution was composed of the following: $130 \mathrm{mmol} / 1 \mathrm{NaCl}, 5.4 \mathrm{mmol} / \mathrm{l} \mathrm{KCl}, 1.8 \mathrm{mmol} / \mathrm{l}$ $\mathrm{CaCl}_{2}, 1 \mathrm{mmol} / 1 \mathrm{MgCl}_{2}, 0.3 \mathrm{mmol} / 1 \mathrm{Na}_{2} \mathrm{HPO}_{4}, 10 \mathrm{mmol} / \mathrm{l}$ HEPES and $10 \mathrm{mmol} / \mathrm{l}$ glucose. The $\mathrm{pH}$ of the solution was adjusted to $\mathrm{pH} 7.4$ using $\mathrm{NaOH}$. In addition, $\mathrm{Ca}^{2+}$-free Tyrode's solution was used, without $\mathrm{CaCl}_{2}$. The collagenase solution was composed of $\mathrm{Ca}^{2+}$-free Tyrode's solution containing $0.6 \mathrm{mg} / \mathrm{ml}$ collagenase type II (Invitrogen; Thermo Fisher Scientific, Inc., Waltham, MA, USA), $0.1 \%$ bovine serum albumin, $20 \mathrm{mM}$ taurine and $30 \mu \mathrm{M} \mathrm{CaCl}_{2}$. Kraft-Brühe (KB) solution included $10 \mathrm{mmol} / 1$ taurine, $70 \mathrm{mmol} / 1$ glutamic acid, $25 \mathrm{mmol} / \mathrm{l} \mathrm{KCl}$, $10 \mathrm{mmol} / 1 \mathrm{KH}_{2} \mathrm{PO}_{4}, 22 \mathrm{mmol} / 1$ glucose and $0.5 \mathrm{mmol} / 1$ ethylene glycol tetraacetic acid (EGTA). The $\mathrm{pH}$ of the KB solution was adjusted to $\mathrm{pH} 7.2$ using $\mathrm{KOH}$. Tyrode's solution was supplemented with 10, 30, 100 and $300 \mu \mathrm{mol} / 1$ allicin during allicin treatment. Furthermore, the pipette solution used in the study 
A

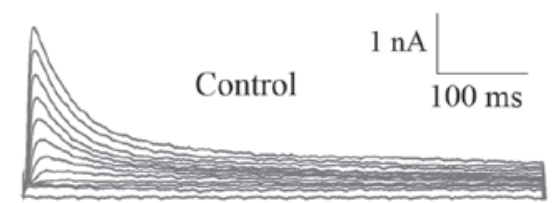

C

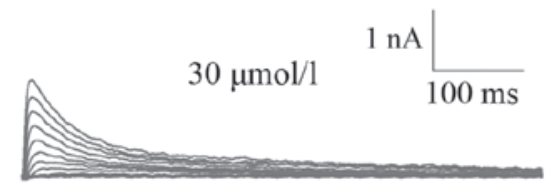

B

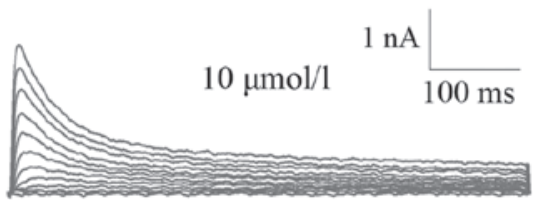

D

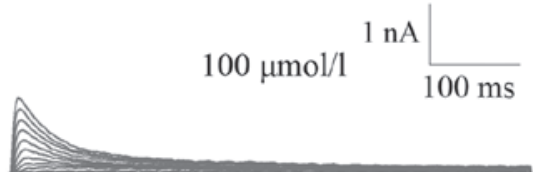

$\mathbf{E}$

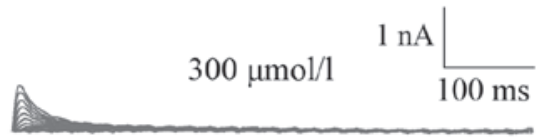

Figure 1. Effects of allicin on transient outward potassium currents $\left(\mathrm{I}_{\mathrm{to}}\right)$ in mouse ventricular myocytes. The data reveal the representative voltage-dependent $\mathrm{I}_{\text {to }}$ (A) under control conditions, and (B) in the presence of $10 \mu \mathrm{mol} / 1$ allicin, (C) $30 \mu \mathrm{mol} / 1 \mathrm{allicin}$, (D) $100 \mu \mathrm{mol} / 1$ allicin and (E) $300 \mu \mathrm{mol} / 1 \mathrm{allicin}$. Data are presented as mean \pm standard deviation.

consisted of $110 \mathrm{mmol} / 1 \mathrm{~K}$-aspartate, $20 \mathrm{mmol} / 1 \mathrm{KCl}, 8 \mathrm{mmol} / 1$ $\mathrm{NaCl}, 1 \mathrm{mmol} / 1 \mathrm{MgCl}_{2}, 1 \mathrm{mmol} / \mathrm{CaCl}_{2}, 4 \mathrm{mmol} / 1 \mathrm{MgATP}$, $0.1 \mathrm{mmol} / \mathrm{l}$ EGTA and $10 \mathrm{mmol} / \mathrm{l} \mathrm{HEPES}$, and was adjusted to pH 7.2 using KOH. Allicin was purchased from Xuzhou Ryen Pharm Co., Ltd (Xuzhou, China).

Isolation of ventricular cardiac myocytes. A total of 36 C57BL/6 mice, weighing 25.1 $23.4 \mathrm{~g}$, were heparinized [100 U; intraperitoneal injection (i.p.); Wangbang Co., Xuzhou, China] $15 \mathrm{~min}$ prior to sacrifice, anaesthetized by pentobarbital sodium (60 mg/kg; i.p.; Sigma-Aldrich, St. Louis, MO, USA) and sacrificed by cervical dislocation. Hearts were rapidly removed and retrogradely perfused at a temperature of $37^{\circ} \mathrm{C}$ with the following solutions, according to Langendorff technique (21): i) Tyrode's solution (5 min); ii) $\mathrm{Ca}^{2+}$-free Tyrode's solution (5 min); iii) collagenase solution (15 min); and iv) KB solution (5 min). Subsequent to the perfusion, the left ventricular free wall was dissected from the heart and placed in ice-cold KB solution. The tissue was then minced and titrated to free individual myocytes. Isolated cardiac myocytes were stored in $\mathrm{KB}$ solution at $4^{\circ} \mathrm{C}$ until required.

Electrophysiology recording. Whole-cell patch clamp was performed on the myocytes using an EPC-9 amplifier (Heka Elektronik, Lambrecht, Germany), as previously described (21), and data was recorded and analyzed with a Pulse/Pulsefit software interface (version 8.31; Heka Elektronik). During the experiments, $1.5 \mathrm{ml}$ myocytes were placed in the experimental chamber and mounted on the stage of an inverted microscope (IX70; Olympus Corporation, Tokyo, Japan) and perfused with Tyrode solution supplemented with 10, 30, 100 and $300 \mu \mathrm{mol} / 1$ allicin for $5 \mathrm{~min}$ at a rate of $2-3 \mathrm{ml} / \mathrm{min}$ at room temperature. In order to elucidate the effect of allicin on $\mathrm{I}_{\mathrm{to}}$ in mouse ventricular myocytes, 6 cells were observed per solution influx, in triplicate. Pipettes had resistances of 2.5-3.5 M $\Omega$ when filled with pipette solution. Series resistance (Rs) was between 4-8 M $\Omega$ and was compensated by $80-90 \%$ to reduce the Rs. Current signals were filtered at $3 \mathrm{kHz}$ by an 8 -pole Bessel filter, digitized at a sampling rate of $1 \mathrm{kHz}$ and recorded on a computer running Pulse/Pulsefit software, which was additionally used for the generation of voltage pulses and data analysis.
$I_{\text {to }}$ recording. The total $\mathrm{I}_{\mathrm{to}}$ was determined by $500 \mathrm{msec}$ depolarizing pulses varying from -50 to $+60 \mathrm{mV}$ in $10 \mathrm{mV}$ increments from a holding potential of $-80 \mathrm{mV}$. In order to examine $\mathrm{I}_{\mathrm{to}}$, pre-pulse $(100 \mathrm{msec},-40 \mathrm{mV})$ was used to inactivate $\mathrm{I}_{\text {to }}$ prior to activation steps with allicin, and $\mathrm{I}_{\mathrm{to}}$ was measured by subtracting the currents before and after that pre-pulse. By dividing the measured current amplitude by the membrane capacitance $(\mathrm{pA} / \mathrm{pF}), \mathrm{I}_{\text {to }}$ values were reported as current densities.

The $\mathrm{IC}_{50}$ of allicin on $I_{\text {to }}$ was fitted with Hill function using OriginPro version 8.0 software as follows: $E=E_{\max }[1+(D / C) b]$, where $\mathrm{E}$ is the effect at concentration $\mathrm{C}, \mathrm{E}_{\max }$ is the maximum effect, $\mathrm{D}$ is the concentration for half-maximum action $\left(\mathrm{IC}_{50}\right)$ and $b$ is the Hill coefficient.

Steady-state activation curve of $I_{t o}$. Using the current-voltage (I-V) association for $\mathrm{I}_{\mathrm{to}}$, the voltage-dependent of steady-state activation curve for $\mathrm{I}_{\mathrm{to}}$ was fitted to the Boltzmann equation as follows: $\mathrm{I} / \mathrm{I}_{\max }=1 /\left[1+\exp \left(\left(\mathrm{V}_{\mathrm{T}}-\mathrm{V}_{1 / 2}\right) / \mathrm{k}\right)\right]$, where $\mathrm{I}_{\max }$ is maximum current, $\mathrm{V}_{\mathrm{T}}$ is the membrane potential, $\mathrm{V}_{1 / 2}$ is the midpoint potential for activation and $\mathrm{K}$ is a slope factor (22).

Steady-state inactivation of $I_{t o}$. The two-step voltage-clamp protocol was applied for steady-state inactivation of $\mathrm{I}_{\mathrm{to}}$, as previously described (21). The process involved an inactivating pre-pulse period that varied from $-110 \mathrm{mV}$ to $+10 \mathrm{mV}$ with a $1 \mathrm{sec}$ pre-pulse, followed by a fixed $400 \mathrm{~ms}$ test pulse to $+40 \mathrm{mV}$. The test current amplitude of $\mathrm{I}_{\mathrm{to}}$ at each pulse potential was normalized to the maximal amplitude of this current $\left(\mathrm{I} / \mathrm{I}_{\max }\right)$. Data were fitted to the Boltzmann equation.

Recovery from inactivation of $I_{t o}$. The time-dependence of reactivation was measured using an inactivating pulse (-40 mV, maintained for $500 \mathrm{msec}$ ). Following this, at variable time intervals (10-200 msec), a $500 \mathrm{msec}$ test pulse at $+40 \mathrm{mV}$ was performed. The ratio of the current amplitude produced by the test pulse to the inactivating pulse (P2/P1) was plotted as a function of the time intervals. The time constant was calculated by data fitted to exponential functions.

Statistical analysis. All data are expressed as the mean \pm standard deviation. Statistical analysis was performed using 


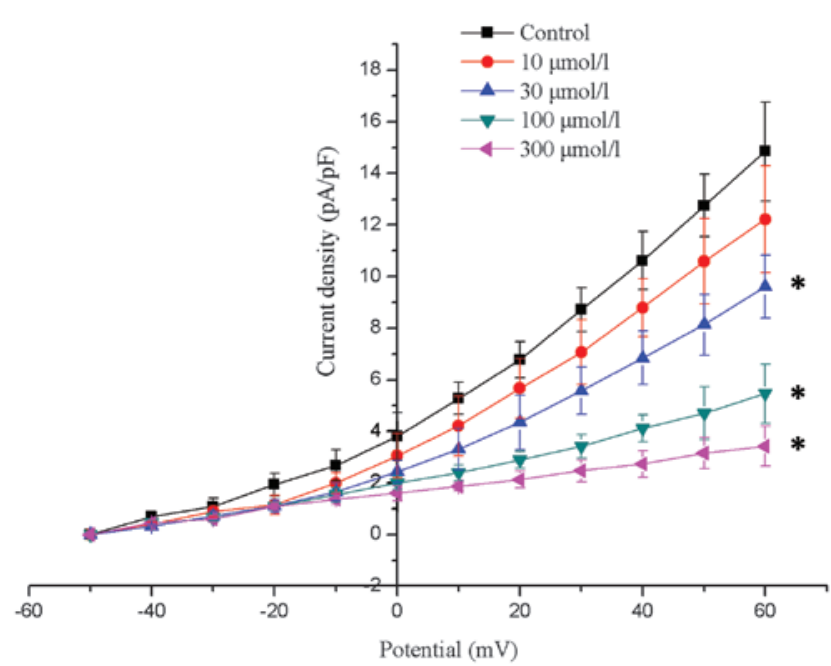

Figure 2. Current-voltage association for $\mathrm{I}_{\text {to }}$ in mouse ventricular myocytes following treatment with various allicin concentrations. Allicin inhibited $\mathrm{I}_{\text {to }}$ in a concentration-dependent manner. Data are presented as the mean \pm standard deviation. " $\mathrm{P}<0.05$ vs. control, $\mathrm{n}=6$. $\mathrm{I}_{\mathrm{to}}$, transient outward potassium current.

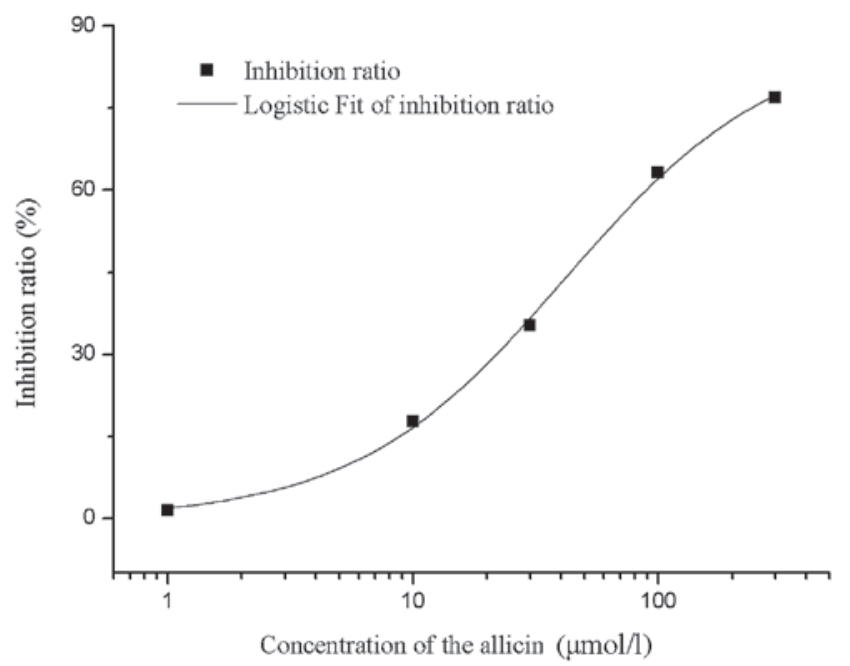

Figure 3. Dose-response association for inhibition of $\mathrm{I}_{\mathrm{to}}$ by allicin. At a potential of $+60 \mathrm{mV}$, treatment with 1,10,30,100 and $300 \mu \mathrm{mol} / 1$ allicin decreased the peak $\mathrm{I}_{\text {to }}$ current by $1.5,17.8,35.3,63.2$ and $76.9 \%$, respectively. The $\mathrm{IC}_{50}$ of allicin on $\mathrm{I}_{\text {to }}$ was fitted with Hill function and calculated to be $41.6 \mu \mathrm{mol} / 1$, using OriginPro version 8.0 software $(n=6) . I_{t o}$, transient outward potassium current.

a Student's t test and analysis of variance, performed on SPSS version 17.0 software (SPSS, Inc. Chicago, IL, USA). Patch-clamp data were analyzed using Origin version 8.0 (OriginLab Corporation, Northampton, MA, USA). P<0.05 was considered to indicate a statistically significant difference.

\section{Results}

Effects of allicin on voltage-dependent $I_{\text {to }}$. Allicin at 10, 30, 100 and $300 \mu \mathrm{mol} / 1$ was applied, respectively. $\mathrm{I}_{\text {to }}$ was blocked by allicin in a concentration-dependent manner. Currents were gradually decreased with the increase of allicin concentration.

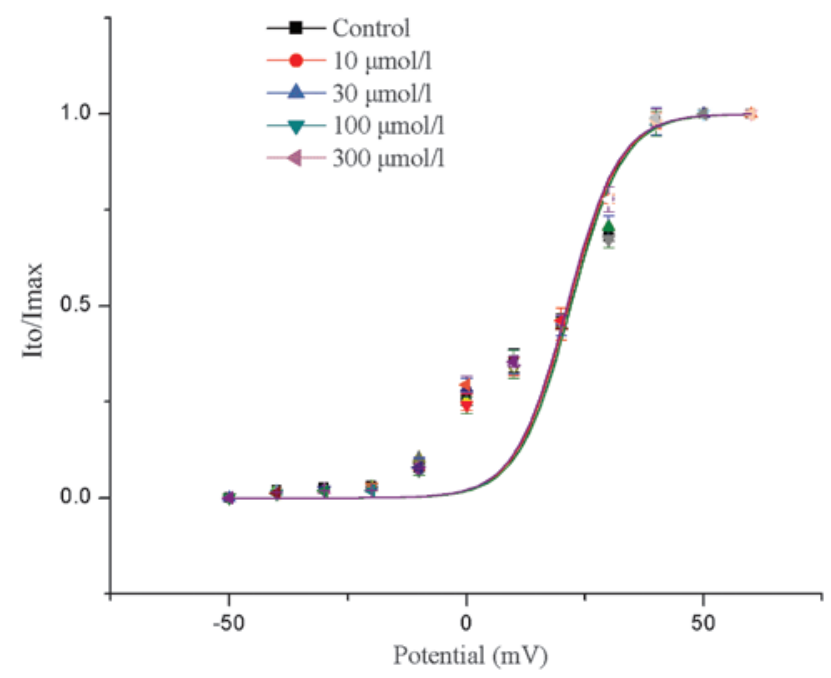

Figure 4. Voltage-dependent activation curve of $\mathrm{I}_{\text {to }}$ using the current-voltage association for $\mathrm{I}_{\mathrm{to}}$. Allicin had no significant effect on the voltage-dependence of the steady-state activation curve of $\mathrm{I}_{\text {to }}(\mathrm{P}>0.05)$. Data are presented as the mean \pm standard deviation. $I_{\text {to }}$, transient outward potassium current; $I_{\max }$, maximum current.

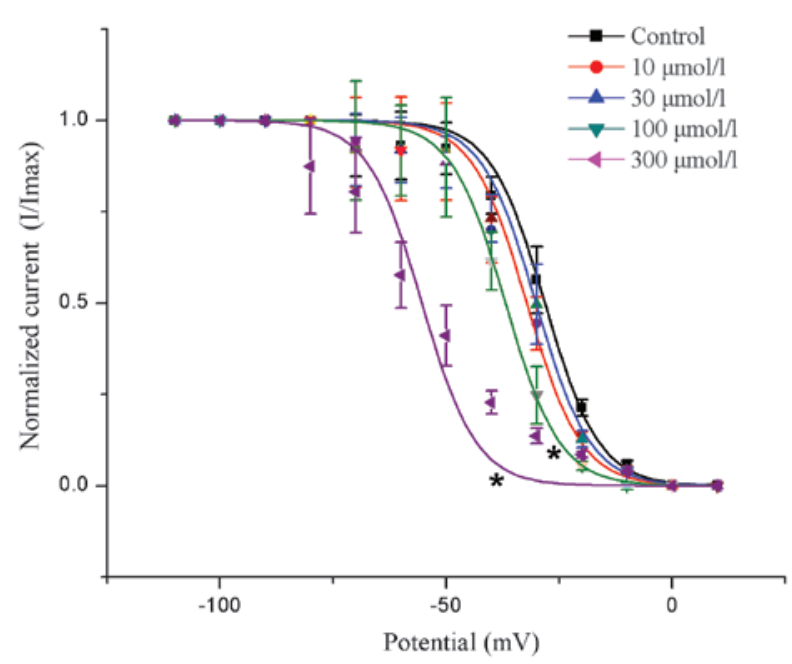

Figure 5. Voltage dependence of the inactivation ( $\left.\mathrm{I} / \mathrm{I}_{\max }\right)$ of $\mathrm{I}_{\mathrm{to}}$ following treatment with various allicin concentrations. The voltage dependence of the inactivation of $\mathrm{I}_{\text {to }}$ was negatively shifted after treatment with high concentrations of allicin (100 and $300 \mu \mathrm{mol} / 1$; ${ }^{*} \mathrm{P}<0.05$ vs. control; $\mathrm{n}=6$ ).Data are presented as the mean \pm standard deviation. $\mathrm{I} / \mathrm{I}_{\max }$, current $/$ maximum current; $\mathrm{I}_{\mathrm{to}}$, transient outward potassium current.

The representative current blocked by allicin at 10, 30, 100 and $300 \mu \mathrm{mol} / 1$ is shown in Fig. 1.

Fig. 2 displays the $\mathrm{I}-\mathrm{V}$ association for $\mathrm{I}_{\mathrm{to}}$ density prior to and following the application of 10, 30, 100 and $300 \mu \mathrm{mol} / 1$ allicin. The $\mathrm{I}_{\mathrm{to}}$ was not significantly suppressed by allicin in the low dose (10 $\mu \mathrm{mol} / \mathrm{l} ; \mathrm{P}>0.05)$; however, it was significantly suppressed by higher doses $(30,100$ and $300 \mu \mathrm{mol} / \mathrm{l} ; \mathrm{P}<0.05$; $\mathrm{n}=6$ ) compared with the control.

In addition, Fig. 3 shows the dose-response association for the inhibition of $I_{t o}$ by allicin. At a potential of $+60 \mathrm{mv}$, treatment with $1,10,30,100$ and $300 \mu \mathrm{mol} / 1$ allicin decreased the peak $I_{\text {to }}$ by $1.5,17.8,35.3,63.2$ and $76.9 \%$, respectively. The $\mathrm{IC}_{50}$ of allicin on $\mathrm{I}_{\text {to }}$ was fitted with Hill function and calculated 


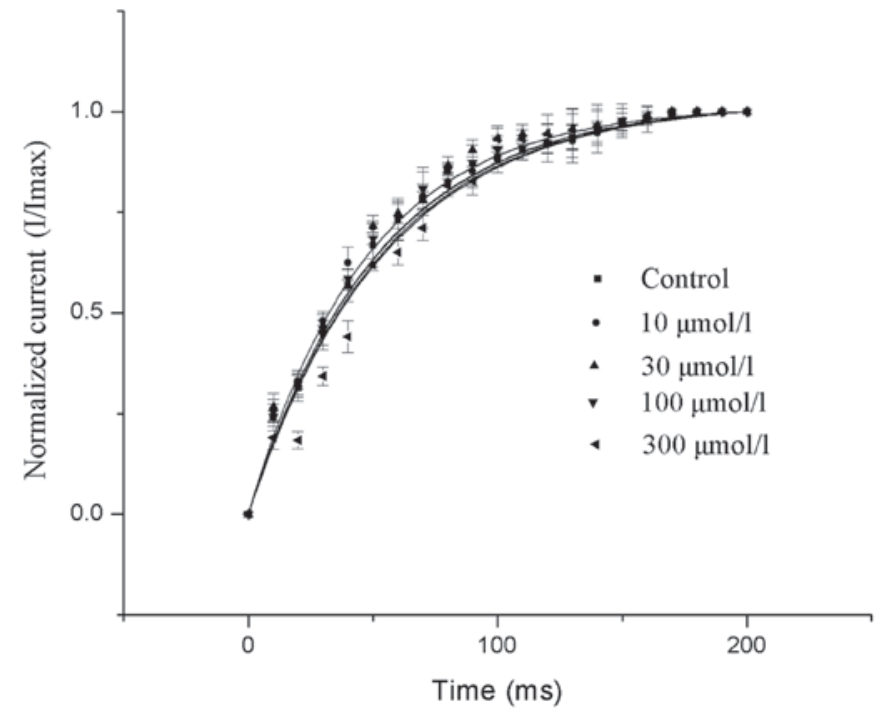

Figure 6. Effects of allicin on recovery from the inactivation of $\mathrm{I}_{\mathrm{to}}$. Allicin was not found to have a significant effect on the recovery from the inactivation of $\mathrm{I}_{\text {to }}\left(\mathrm{P}>0.05\right.$ vs. control). $\mathrm{I}_{\text {to }}$, transient outward potassium current; $\mathrm{I} / \mathrm{I}_{\max }$, current / maximum current.

as $41.6 \mu \mathrm{mol} / \mathrm{l}(\mathrm{n}=6$ cells in each group) using OriginPro 8.0 software.

Effects of allicin on the steady-state activation curve of $I_{t o}$. Allicin was not found to have a significant effect on the voltage-dependence of the steady-state activation curve of $\mathrm{I}_{\text {to }}$ ( $\mathrm{P}>0.05$; Fig. 4).

Effects of allicin on the steady-state inactivation of $I_{t o}$. The results revealed that a low dose of allicin had no significant effect on the voltage-dependence of the inactivation $\left(\mathrm{I} / \mathrm{I}_{\max }\right.$ ) of $\mathrm{I}_{\text {to }}$ (control, $\mathrm{V}_{1 / 2}=-28.2 \pm 4.7 \mathrm{mV} ; 10 \mu \mathrm{mol} / 1$ allicin, $\mathrm{V}_{1 / 2}=-32.2 \pm 3.8 \mathrm{mV} ; 30 \mu \mathrm{mol} / 1$ allicin, $\mathrm{V}_{1 / 2}=-30.1 \pm 3.6 \mathrm{mV}$; $\mathrm{n}=6 ; \mathrm{P}>0.05$, compared with the control). However, as shown in Fig. 5, high doses of allicin significantly shifted the voltage-dependence of the inactivation of $\mathrm{I}_{\mathrm{to}}$ toward the negative potential $\left(100 \mu \mathrm{mol} / 1\right.$ allicin, $\mathrm{V}_{1 / 2}=-36.9 \pm 4.1 \mathrm{mV}$; $300 \mu \mathrm{mol} / 1$ allicin, $\mathrm{V}_{1 / 2}=-55.3 \pm 5.0 \mathrm{mV} ; \mathrm{n}=6 ; \mathrm{P}<0.05$ compared with the control).

Effects of allicin on the recovery from inactivation of $I_{t o}$. Allicin was not found to have a significant effect on the recovery from the inactivation of $\mathrm{I}_{\mathrm{to}}$ following allicin treatment $(\mathrm{P}>0.05$; Fig. 6).

\section{Discussion}

In the present study, allicin significantly inhibited $\mathrm{I}_{\text {to }}$ in mouse ventricular myocytes in a concentration-dependent manner. High-dose allicin ( $\geq 100 \mu \mathrm{mol} / \mathrm{l})$ was able to significantly shift the voltage-dependence of the steady-state inactivation curve of $I_{\text {to }}$ towards an increasingly negative potential. However, allicin did not have a significant effect on steady-state activation, or recovery from the inactivation of $\mathrm{I}_{\mathrm{to}}$.

Traditional Chinese medicine has been used for thousands of years for the treatment of cardiovascular diseases $(23,24)$.
In recent decades, garlic has been found to possess antiarrhythmic effects $(13,14)$. Several reports $(25-27)$ have indicated that allicin is the predominant active component that is responsible for the majority of the biological activities of garlic, including attenuating ischemic injury, lowering blood pressure and antiarrhythmic effects $(6,28,29)$. The chemical structure of allicin is $\mathrm{CH}_{2}=\mathrm{CH}-\mathrm{CH}_{2}-\mathrm{S}(\mathrm{O})-\mathrm{S}-\mathrm{CH}_{2}-\mathrm{CH}=\mathrm{CH}_{2}$, and it has been has been manufactured synthetically and produced worldwide (18). Although garlic has been discovered to be a significant antiarrhythmic agent, the exact mechanism has yet to be elucidated.

In the present study, allicin significantly inhibited $I_{t o}$ in mouse ventricular myocytes; however, it had no significant effect on steady-state activation, or recovery from inactivation of $I_{t o}$, which is in agreement with previous findings (20). In the study by Deng et al (20), the research target was human atrial myocytes, and it was demonstrated that $30 \mu \mathrm{mol} / 1$ allicin was able to negatively shift the voltage-dependence of the steady-state inactivation curve of $\mathrm{I}_{\mathrm{to}}$. By contrast, in the present study, only high-dose allicin ( $\geq 100 \mu \mathrm{mol} / \mathrm{l})$ was able to significantly shift the steady-state inactivation curve of $\mathrm{I}_{\text {to }}$ towards an increasingly negative potential. This may be due to allicin having different effects in different tissues and species. Allicin exerts its suppressive effect on $\mathrm{I}_{\text {to }}$ by changing the quantity and kinetic properties of $\mathrm{I}_{\mathrm{to}}$. In human atrial monocytes, $\mathrm{I}_{\mathrm{to}}$ contributes to cardiac repolarization, whilst in the hearts of mice, $\mathrm{I}_{\text {to }}$ has a role in action potential repolarization $(30,31)$. Notably, $I_{\text {to }}$ is not uniformly distributed within the left ventricle in humans, mice and certain other mammals (32-35). In the left ventricular free wall, $I_{\text {to }}$ is larger in epicardial compared with endocardial regions, which contributes to the regional variations of action potential (AP) profiles and results in a prominent AP notch in the epicardium, but not in the endocardium (36). It has been confirmed that a prominent $\mathrm{I}_{\mathrm{to}}$ is important in physiological and pathophysiological process (37-41). The high incidence of phase 2 reentry and ventricular fibrillation during myocardial ischemia was partly due to the prominent $\mathrm{I}_{\mathrm{to}}$-mediated epicardial AP dome (42). In patients with coronary heart disease, the incidence of sudden mortality in men was significantly higher compared with that in women $(43,44)$. This may be a result of a more prominent $\mathrm{I}_{\mathrm{to}}$ in men compared with women (39). Thus, $\mathrm{I}_{\text {to }}$ block may be an effective therapy for arrhythmia (37).

In the present study, it was revealed that allicin was able to inhibit $\mathrm{I}_{\mathrm{to}}$, and may be the mechanism through which allicin exerts its antiarrhythmic effect. Antiarrhythmic therapeutics with low toxicity and low reverse use-dependence (RUD) effects are a focal point in antiarrhythmic drug research. Xing et al (23) confirmed that allicin has similar effects to amiodarone on the conduction system and cardiac electrophysiology. However, allicin possesses no RUD and this may contribute to multi-channel blockers. Furthermore, allicin appears to be safe for use in the majority of conditions (2) and is therefore likely to be a promising antiarrhythmic therapy.

In conclusion, the present study revealed that allicin inhibits $I_{t o}$ in mouse ventricular myocytes, which may be the mechanism through which allicin exerts its antiarrhythmic effect. Thus, allicin has demonstrated potential to be a promising antiarrhythmic therapy in the future; however, whether allicin exerts the same effect in other tissues or species requires further investigation. 


\section{Acknowledgements}

The present study was financially supported by the Fundamental Research Funds for the Central Universities (grant no. 2012302020205).

\section{References}

1. Lan H and Lü YY: Allitridi induces apoptosis by affecting Bcl-2 expression and caspase-3 activity in human gastric cancer cells. Acta Pharmacol Sin 25: 219-225, 2004

2. Aviello G, Abenavoli L, Borrelli F, Capasso R, Izzo AA, Lembo F, Romano B and Capasso F: Garlic: Empiricism or science? Nat Prod Commun 4: 1785-1796, 2009.

3. Seki T, Hosono T, Hosono-Fukao T, Inada K, Tanaka R, Ogihara J and Ariga T: Anticancer effects of diallyl trisulfide derived from garlic. Asia Pac J Clin Nutr 17 (Suppl 1): S249-S252, 2008.

4. Qureshi AA, Abuirmeileh N, Din ZZ, Elson CE and Burger WC: Inhibition of cholesterol and fatty acid biosynthesis in liver enzymes and chicken hepatocytes by polar fractions of garlic. Lipids 18: 343-348, 1983.

5. Gebhardt R: Multiple inhibitory effects of garlic extracts on cholesterol biosynthesis in hepatocytes. Lipids 28: 613-619, 1993

6. Malik ZA and Siddiqui S: Hypotensive effect of freeze-dried garlic (Allium Sativum) sap in dog. J Pak Med Assoc 31: 12-13, 1981.

7. Boullin DJ: Garlic as a platelet inhibitor. Lancet 1: 776-777, 1981

8. Gaffen JD, Tavares IA and Bennett A: The effect of garlic extracts on contractions of rat gastric fundus and human platelet aggregation. J Pharm Pharmacol 36: 272-274, 1984.

9. Srivastava KC: Evidence for the mechanism by which garlic inhibits platelet aggregation. Prostaglandins Leukot Med 22: 313-321, 1986

10. Apitz-Castro R, Cabrera S, Cruz MR, Ledezma E and Jain MK Effects of garlic extract and of three pure components isolated from it on human platelet aggregation, arachidonate metabolism, release reaction and platelet ultrastructure. Thromb Res 32: 155-169, 1983.

11. Ciplea AG and Richter KD: The protective effect of Allium sativum and crataegus on isoprenaline-induced tissue necroses in rats. Arzneimittelforschung 38: 1583-1592, 1988

12. Siegers CP, Röbke A and Pentz R: Effects of garlic preparations on superoxide production by phorbol ester activated granulocytes. Phytomedicine 6: 13-16, 1999.

13. Banerjee SK and Maulik SK: Effect of garlic on cardiovascular disorders: A review. Nutr J 1: 4, 2002.

14. Isensee H, Rietz B and Jacob R: Cardioprotective actions of garlic (Allium sativum). Arzneimittelforschung 43: 94-98, 1993.

15. Rietz B, Belagyi J, Török B and Jacob R: The radical scavenging ability of garlic examined in various models. Boll Chim Farm 134: 69-76, 1995.

16. Sungnoon R, Kanlop N, Chattipakorn SC, Tawan R and Chattipakorn N: Effects of garlic on the induction of ventricular fibrillation. Nutrition 24: 711-716, 2008.

17. Sungnoon R, Shinlapawittayatorn K, Chattipakorn SC and Chattipakorn N: Effects of garlic on defibrillation efficacy. Int J Cardiol 126: 143-144, 2008.

18. Martín N, Bardisa L, Pantoja C, Román R and Vargas $M$ Experimental cardiovascular depressant effects of garlic (Allium sativum) dialysate. J Ethnopharmacol 37: 145-149, 1992.

19. Martín N, Bardisa L, Pantoja C, Vargas M, Quezada P and Valenzuela J: Anti-arrhythmic profile of a garlic dialysate assayed in dogs and isolated atrial preparations. J Ethnopharmacol 43 $1-8,1994$.

20. Deng CY, Rao F, Kuang SJ, Wu SL, Shan ZX, Li XH, Zhou ZL, Lin QX, Liu XY, Yang M, et al: Allitridi inhibits transient outward potassium currents in human atrial myocytes. Clin Exp Pharmacol Physiol 38: 323-327, 2011.

21. Qin M, Huang H, Wang T, Hu H, Liu Y, Cao H, Li H and Huang C: Absence of Rgs5 prolongs cardiac repolarization and predisposes to ventricular tachyarrhythmia in mice. J Mol Cell Cardiol 53: 880-890, 2012

22. Brouillette J, Clark RB, Giles WR and Fiset C: Functional properties of $\mathrm{K}^{+}$currents in adult mouse ventricular myocytes. J Physiol 559: 777-798, 2004
23. Xing Y, Chen J, Wang J, Gao Y, Niu W, Zhao M, Zhu H, Guo L, Lu P, Wang S: The effects of allitridi and amiodarone on the conduction system and reverse use-dependence in the isolated hearts of rats with myocardial infarction. J Ethnopharmacol 141: 674-684, 2012.

24. Wang X, Wang X, Gu Y, Wang T and Huang C: Wenxin Keli attenuates ischemia-induced ventricular arrhythmias in rats: Involvement of L-type calcium and transient outward potassium currents. Mol Med Rep 7: 519-524, 2013.

25. Batirel HF, Naka Y, Kayano K, Okada K, Vural K, Pinsky DJ and $\mathrm{Oz} \mathrm{MC}$ : Intravenous allicin improves pulmonary blood flow after ischemia-reperfusion injury in rats. J Cardiovasc Surg (Torino) 43: 175-179, 2002.

26. Lawson LD, Ransom DK and Hughes BG: Inhibition of whole blood platelet-aggregation by compounds in garlic clove extracts and commercial garlic products. Thromb Res 65: 141-156, 1992.

27. Prasad K, Laxdal VA, Yu M and Raney BL: Antioxidant activity of allicin, an active principle in garlic. Mol Cell Biochem 148: 183-189, 1995.

28. Banerjee SK, Dinda AK, Manchanda SC and Maulik SK: Chronic garlic administration protects rat heart against oxidative stress induced by ischemic reperfusion injury. BMC Pharmacol 2: 16 , 2002.

29. Martin N, Bardisa L, Pantoja C, Vargas M, Quezada P and Valenzuela J: Anti-arrhythmic profile of a garlic dialysate assayed in dogs and isolated atrial preparations. J Ethnopharmacol 43: $1-8,1994$.

30. Barry DM, Xu H, Schuessler RB and Nerbonne JM: Functional knockout of the transient outward current, long-QT syndrome, and cardiac remodeling in mice expressing a dominant-negative Kv4 alpha subunit. Circ Res 83: 560-567, 1998

31. Nerbonne JM and Kass RS: Molecular physiology of cardiac repolarization. Physiol Rev 85: 1205-1253, 2005.

32. Näbauer M: Electrical heterogeneity in the ventricular wall-and the M cell. Cardiovasc Res 40: 248-250, 1998.

33. Guo W, Xu H, London B and Nerbonne JM: Molecular basis of transient outward $\mathrm{K}+$ current diversity in mouse ventricular myocytes. J Physiol 3: 587-599, 1999.

34. Näbauer M, Beuckelmann DJ, Uberfuhr P and Steinbeck G: Regional differences in current density and rate-dependent properties of the transient outward current in subepicardial and subendocardial myocytes of human left ventricle. Circulation 93: 168-177, 1996.

35. Wickenden AD, Jegla TJ, Kaprielian R and Backx PH: Regional contributions of Kv1.4, Kv4.2 and Kv4.3 to transient outward $\mathrm{K}^{+}$ current in rat ventricle. Am J Physiol 276: H1599-H1607, 1999.

36. Akar FG, Wu RC, Deschenes I, Armoundas AA, Piacentino V III, Houser SR and Tomaselli GF: Phenotypic differences in transient outward $\mathrm{K}+$ current of human and canine ventricular myocytes: Insights into molecular composition of ventricular Ito. Am J Physiol Heart Circ Physiol 286: H602-H609, 2004.

37. Yan GX and Antzelevitch C: Cellular basis for the Brugada syndrome and other mechanisms of arrhythmogenesis associated with ST-segment elevation. Circulation 100: 1660-1666, 1999.

38. Yan GX, Lankipalli RS, Burke JF, Musco S and Kowey PR: Ventricular repolarization components on the electrocardiogram: Cellular basis and clinical significance. J Am Coll Cardiol 42: 401-409, 2003.

39. Di Diego JM, Cordeiro JM, Goodrow RJ, Fish JM, Zygmunt AC, Pérez GJ, Scornik FS and Antzelevitch C: Ionic and cellular basis for the predominance of the Brugada syndrome phenotype in males. Circulation 106: 2004-2011, 2002.

40. Yan GX and Antzelevitch C: Cellular basis for the electrocardiographic J wave. Circulation 93: 372-379, 1996.

41. Di Diego JM, Sun ZQ and Antzelevitch C: I(to) and action potential notch are smaller in left vs. right canine ventricular epicardium. Am J Physiol 271: H548-H561, 1996.

42. Yan GX, Joshi A, Guo D, Hlaing T, Martin J, Xu X and Kowey PR: Phase 2 reentry as a trigger to initiate ventricular fibrillation during early acute myocardial ischemia. Circulation 110 : 1036-1041, 2004

43. Lerner DJ and Kannel WB: Patterns of coronary heart disease morbidity and mortality in the sexes: A 26-year follow-up of the Framingham population. Am Heart J 111: 383-390, 1986.

44. Every N, Hallstrom A, McDonald KM, Parsons L, Thom D, Weaver D and Hlatky MA: Risk of sudden versus nonsudden cardiac death in patients with coronary artery disease. Am Heart J 144: 390-396, 2002. 